\title{
Estimating the population density of Mongolian gazelles Procapra gutturosa by driving long-distance transects
}

\author{
Kirk A. Olson, Todd K. Fuller, George B. Schaller, Daria Odonkhuu and Martyn G. Murray
}

\begin{abstract}
Despite a $\geq 75 \%$ reduction in the geographic range of Mongolian gazelles Procapra gutturosa over the past 50 years, the species is still recognized as the most numerous large grassland herbivore in Asia. Its actual population size, however, is still disputed, and we therefore estimated its numbers in an $80,000 \mathrm{~km}^{2}$ area in the eastern steppe of Mongolia by driving long-distance $(1,200-1,400 \mathrm{~km})$ transect surveys during spring and autumn 2000-2002. Quantitative estimates of gazelle numbers are essential for understanding the causes of changes in the population, and thus devising conservation strategies to assure its long-term viability. Observed herds ranged in size from 1-4,000; among surveys, median herd sizes varied from $14-42$. Density estimates
\end{abstract}

varied from 10.7 gazelles $\mathrm{km}^{-2}$ in spring to 11.5 gazelles $\mathrm{km}^{-2}$ in autumn, with total population estimates of 803,820 (483,790-1,330,100 95\% confidence interval) and 870,625 (499,432-1,491,278 95\% confidence interval), respectively. Confidence limits were wide, and to obtain a coefficient of variation of $20 \%$, transect lengths would need to be extended three- to four-fold. Until more efficient means for conducting population surveys can be implemented, driving long-distance transects, combined with distance analysis, seem to provide the best quantitative estimate of Mongolian gazelle populations.

Keywords Density, distance sampling, estimate, gazelles, line transects, Mongolia, population, Procapra gutturosa.

\section{Introduction}

In the past 50 years the range of the Mongolian gazelle Procapra gutturosa was reduced by up to $75 \%$ in Mongolia (from $780,000 \mathrm{~km}^{2}$ in the 1940 s to as low as $190,000 \mathrm{~km}^{2}$ in 1997) and Inner Mongolia, China (from $300,000 \mathrm{~km}^{2}$ during $1950-1970$ to $<75,000 \mathrm{~km}^{2}$ in 1995) and virtually eliminated in Russia (Bannikov et al., 1961; Lhagvasuren \& Milner-Gulland, 1997; Xiaoming et al., 1997; Jiang et al., 1998). Despite this, the species is still recognized as 'one of Asia's largest remaining wildlife populations' (Finch, 1996).

Kirk A. Olson Department of Natural Resources Conservation, 160 Holdsworth Way, University of Massachusetts, Amherst, MA 010039285 , USA, and Wildlife Conservation Society, 2300 Southern Boulevard, Bronx, NY 10460, USA.

Todd K. Fuller (Corresponding author) Department of Natural Resources Conservation, 160 Holdsworth Way, University of Massachusetts, Amherst, MA 01003 9285, USA. E-mail tkfuller@forwild.umass.edu

George B. Schaller Wildlife Conservation Society, 2300 Southern Boulevard, Bronx, NY 10460, USA.

Daria Odonkhuu Ecology Department, National University of Mongolia, Ikh Surguuliin Gudamj, Building 2, Ulaanbaatar, Mongolia.

Martyn G. Murray Institute of Cell, Animal, and Population Biology, Ashworth Labs, West Mains Road, Edinburgh, EH9 3JT, UK.

Received 21 May 2004. Revision requested 2 July 2004. Accepted 3 November 2004.
For centuries Mongolian pastoralists have utilized Mongolian gazelles as a supplement to their diet, and for much of the past century the population has been harvested for commercial purposes (Milner-Gulland \& Lhagvasuren, 1998; Reading et al., 1998; Sampildendev, 2000). Recently, a moratorium was placed on large-scale harvesting for export, but widespread poaching and hunting for local markets still occurs (Scharf \& Enkhbold, 2002). Despite the cultural and economic importance of this species its actual population size has been the subject of controversy and contradictions; partial or total population estimates have ranged from as few as 180,000 to as many as 2,670,000 (Milner-Gulland \& Lhagvasuren, 1998).

Currently there is no consistent standardized monitoring programme for the Mongolian gazelle. A severe population decline in the future due to a disease outbreak (Schaller \& Lhagvasuren, 1998), massive illegal harvest and subsequent reproductive collapse (MilnerGulland et al., 2003), or severe winter weather (Lhagvasuren \& Milner-Gulland, 1997), could: (1) result in a cascading decrease in ecosystem functionality and loss of biodiversity, (2) have a negative impact on traditional subsistence hunting practices, and (3) confound the setting of hunting quotas for what may seem to be a sustainable harvest for promoting conservation. Without regular, quantitative assessment of the population, the conservation of this species cannot be assured. Consequently, we attempted to estimate the population size 
of Mongolian gazelles in part of the Eastern steppe by conducting vehicle transect surveys over a period of several years. We also aimed to assess the rigour needed to identify significant population changes over time.

\section{Study area}

At c. $250,000 \mathrm{~km}^{2}$ Mongolia's eastern steppe is one of the largest intact grazing ecosystems in the world (Finch, 1996). Topography of the steppe is level to undulating over elevations of 600-1,100 m. One major river (Kherlen River) runs from west to east through the centre of the steppe (Fig. 1). We concentrated survey efforts in an $80,000 \mathrm{~km}^{2}$ region in south-eastern Dornod Aimag and eastern Sukhbaatar Aimag. This region is a focal point for development interests such as roads and oil fields (Pentilla, 1994; Asian Development Bank, 2002).

Steppe vegetation is dominated by grasses such as Stipa spp., Cleistogenes spp. and Leymus spp., forbs, particularly Artemisia spp., Allium spp. and Astragulus spp., and sedges Carex spp. For an overview of the vegetation of the eastern steppe, see Gunin et al. (2000) and Jigjidsuren \& Johnson (2003). Potential predators of gazelles are wolves Canis lupus, and raptors such as steppe eagles Aquila rapax and golden eagles Aquila chrysaetos.

\section{Methods}

The study area was divided into seven strips, each $60 \mathrm{~km}$ wide and 50-300 km long (Fig. 1). Starting and stopping points were Chinese-Mongolian border fences or major road crossings following the Kherlen River. Transects were driven from north to south. Using a Global Positioning System (GPS), we kept as close to the transect line as possible. Conditions were almost always favourable to driving straight lines. Four observers participated in all surveys. We attempted to maintain a constant speed of $25-35 \mathrm{~km} \mathrm{hr}^{-1}$. Surveys were conducted in the last half of May and the early part of June in spring 2000 and 2002, in late September and early October in autumn 2001, and in late August and early September in autumn 2002; each survey lasted 12-18 days and covered 1,186-1,398 km (Table 1).

When we sighted gazelles, we attempted to count them with spotting scopes or binoculars before they detected the vehicle and ran out of sight. Using a rangefinder, distance measurements were made following the protocol outlined in Buckland et al. (2001) for sampling objects in clusters. Group size was estimated by counting individual animals or groups.

Distance sampling analysis using the software Distance (Thomas et al., 2003) was used to estimate gazelle densities from line transects. Data preparation and analysis followed the general guidelines of Buckland et al. (2001).

In order to minimize the effects of measurement error, herd locations were placed into intervals for final analysis. Final model selection was chosen based on the lowest AIC (Akaike's Information Criterion) value (Buckland et al., 2001). To minimize the effects of any size bias in detection of clusters as they approached $w$, maximum sighting distance (Drummer \& McDonald, 1987), we regressed $\ln$ (cluster size) against estimated $g(x)$ (detection probability) (Buckland et al., 2001).

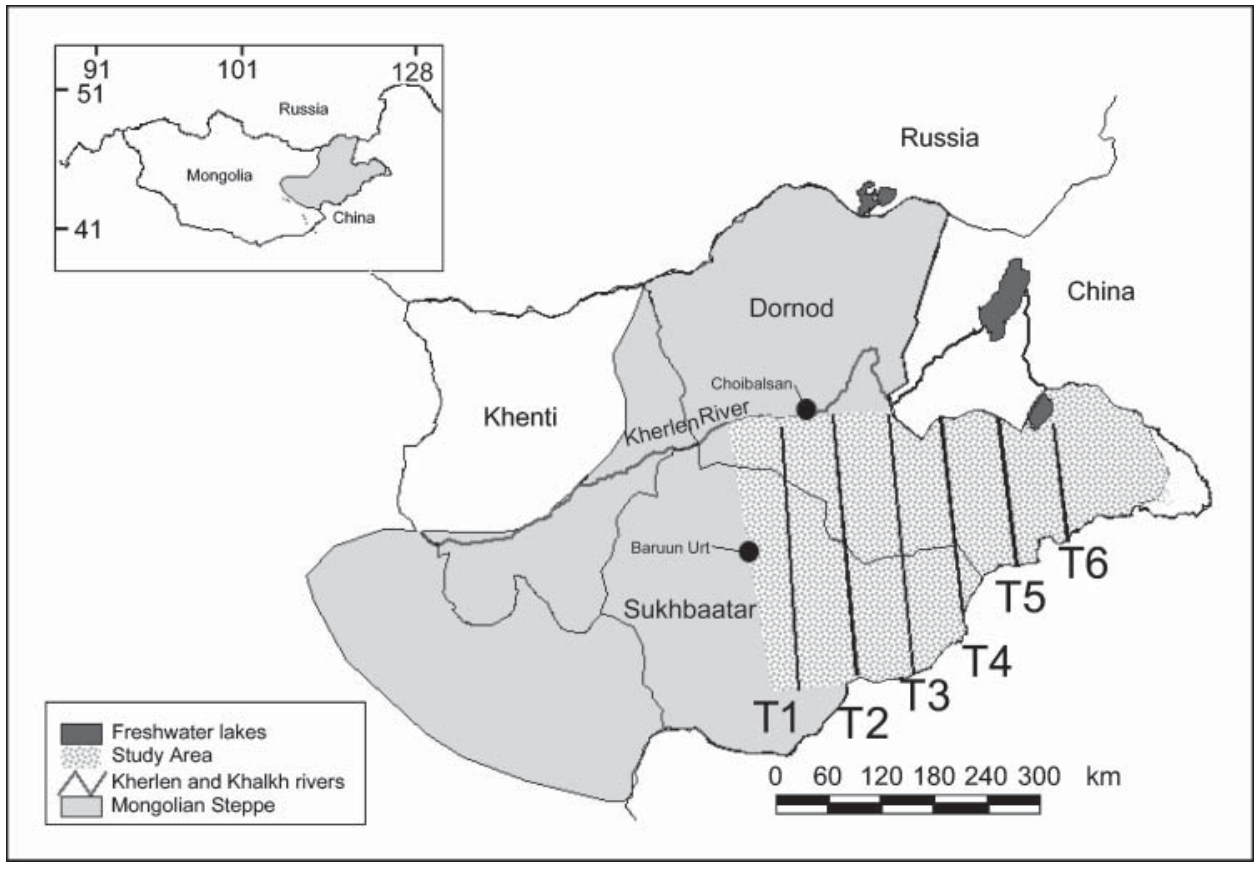

Fig. 1 Study area (shaded) and locations of transects (T1-T6, dashed lines) used to survey Mongolian gazelles in eastern steppe habitat in Mongolia. The inset map shows the position of the main figure within Mongolia. 
Table 1 Survey effort and herd description of the four transect surveys for Mongolian gazelles conducted by vehicle in eastern Mongolia.

\begin{tabular}{|c|c|c|c|c|c|c|c|}
\hline \multirow[b]{2}{*}{ Season } & \multirow[b]{2}{*}{ Year } & \multirow{2}{*}{$\begin{array}{l}\text { Distance } \\
\text { driven }(\mathrm{km})\end{array}$} & \multirow{2}{*}{$\begin{array}{l}\text { No. of } \\
\text { herds }\end{array}$} & \multicolumn{3}{|l|}{ Herd Size } & \multirow{2}{*}{$\begin{array}{l}\text { Total no. } \\
\text { seen }\end{array}$} \\
\hline & & & & Mean \pm SD & Range & Median & \\
\hline \multirow[t]{2}{*}{ Spring } & 2000 & 1,398 & 174 & $161 \pm 442$ & $1-4,000$ & 26 & 27,985 \\
\hline & 2002 & 1,229 & 149 & $96 \pm 221$ & $1-2,000$ & 22 & 14,327 \\
\hline \multirow[t]{2}{*}{ Autumn } & 2001 & 1,356 & 125 & $138 \pm 303$ & $1-2,500$ & 42 & 17,267 \\
\hline & 2002 & 1,186 & 110 & $213 \pm 479$ & $1-2,350$ & 14 & 23,429 \\
\hline
\end{tabular}

Table 2 Strip width, effective strip width, selected models and parameters of the four transect surveys for Mongolian gazelles in eastern Mongolia.

\begin{tabular}{llllllll}
\hline Season & Year & $\begin{array}{l}\text { Strip width } \\
(\mathrm{m})\end{array}$ & $\begin{array}{l}\text { Effective strip } \\
\text { width }(\mathrm{m})\end{array}$ & $\begin{array}{l}\text { No. of } \\
\text { intervals }\end{array}$ & ${ }^{1 \mathrm{P}}$ & ${ }^{2 \mathrm{P}>\chi^{2}}$ & $\begin{array}{l}\text { Model key, } \\
\text { no. of adjustments }\end{array}$ \\
\hline \multirow{2}{*}{ Spring } & 2000 & 1,001 & 440 & 7 & 0.55 & 0.87 & Uniform cosine, 3 \\
& 2002 & 601 & 265 & 6 & 0.44 & 0.19 & Half-normal cosine, 2 \\
\multirow{3}{*}{ Autumn } & 2001 & 650 & 352 & 6 & 0.54 & 0.82 & Uniform cosine, 2 \\
& 2002 & 1,499 & 530 & 4 & 0.35 & 0.30 & Half-normal cosine, 2 \\
\hline
\end{tabular}

${ }^{1}$ Probability of observing an object under the probability detection curve

${ }^{2}$ Probability of a greater chi-square value

We used a z-test to determine if a change in density could be detected between surveys (Buckland et al., 2001). To increase precision of the estimates data for spring and autumn were combined and analysed according to the above procedure. We also used Distance to estimate density based on an 800-m strip (400 m each side), using the uniform key with no adjustments, for comparison between distance sampling analyses and strip transect analyses, the latter being simpler to analyse.

\section{Results}

We counted 110-174 groups of 1-4,000 gazelles during the surveys; among years, mean group size was 96-213 and median group size 14-42 (Table 1). For distance sampling analyses, selected strip widths varied between 601 and 1,499 m, and uniform-cosine or half normalcosine models provided the best fit at the centre lines of the transects (i.e. where observability is assumed to be 1.0; Table 2). The contribution of small clusters to the overall estimated population size was minimal (Table 3 ).

In the $80,000 \mathrm{~km}^{2}$ survey area, densities estimated from distance sampling analyses in spring were 9.9-11.5 gazelles $\mathrm{km}^{-2}$, averaging 10.7 gazelles $\mathrm{km}^{-2}$, giving a point estimate of $c$. 800,000 (Table 4). Densities in autumn were $5.4-15.8$ gazelles $\mathrm{km}^{-2}$, averaging 11.5 gazelles $\mathrm{km}^{-2}$, or $c .870,000$ gazelles in total, similar to the spring estimate (Table 4$)$. There were no detectable differences in densities among surveys $(P \geq 0.22)$. Combined seasons provided more precise estimates (Table 4);
Table 3 Density of herds observed, frequency observed per km, and estimated herd size (cluster size) by size-biased regression, for four transect surveys for Mongolian gazelles in eastern Mongolia.

\begin{tabular}{lcllr}
\hline Season & Year & $\begin{array}{l}\text { Density } \pm \text { SE } \\
\left(\text { per km }{ }^{2}\right)\end{array}$ & $\begin{array}{l}\text { Frequency } \pm \text { SE } \\
\text { (per km) }\end{array}$ & \multicolumn{1}{l}{$\begin{array}{l}\text { Cluster } \\
\text { size } \pm \text { SE }\end{array}$} \\
\hline Spring & 2000 & $0.11 \pm 0.02$ & $0.09 \pm 0.02$ & $109 \pm 32$ \\
& 2002 & $0.17 \pm 0.04$ & $0.09 \pm 0.02$ & $58 \pm 16$ \\
Autumn & 2001 & $0.12 \pm 0.04$ & $0.08 \pm 0.02$ & $134 \pm 34$ \\
& 2002 & $0.08 \pm 0.02$ & $0.09 \pm 0.02$ & $63 \pm 23$ \\
\hline
\end{tabular}

Table 4 Density and population estimates from line transect surveys, driven in the eastern steppe of Mongolia during 2000 to 2002 , calculated by distance sampling and strip transect $(800 \mathrm{~m}$ width) analyses.

\begin{tabular}{|c|c|c|c|}
\hline Season & Year & $\begin{array}{l}\text { Density } \pm \text { SE } \\
\left(\text { per } \mathrm{km}^{2}\right)\end{array}$ & $\begin{array}{l}\text { Population } \\
\text { estimate }(95 \% \mathrm{CI})\end{array}$ \\
\hline \multicolumn{4}{|c|}{ Distance sampling analysis } \\
\hline \multirow[t]{2}{*}{ Spring } & 2000 & $11.5 \pm 4.1$ & $860,380(431,460-1,715,700)$ \\
\hline & 2002 & $9.9 \pm 3.6$ & $742,460(408,020-1,351,000)$ \\
\hline \multicolumn{2}{|l|}{ Combined } & $10.7 \pm 2.8$ & $803,820(483,790-1,330,100)$ \\
\hline \multirow[t]{2}{*}{ Autumn } & 2001 & $15.8 \pm 6.3$ & $1,186,000(537,100-2,619,000)$ \\
\hline & 2002 & $5.4+2.3$ & $401,320(177,150-909,120)$ \\
\hline \multicolumn{2}{|l|}{ Combined } & $11.5 \pm 3.2$ & $870,625(499,432-1,491,278)$ \\
\hline \multicolumn{4}{|c|}{ Strip transect analysis } \\
\hline \multirow[t]{2}{*}{ Spring } & 2000 & $16.3(7.5-35.4)$ & $1,218,800(559,330-2,655,800)$ \\
\hline & 2002 & $6.9(3.6-13.2)$ & $514,600(266,920-990,020)$ \\
\hline \multicolumn{2}{|l|}{ Combined } & $9.3(5.2-16.6)$ & $694,080(388,110-1,241,300)$ \\
\hline \multirow[t]{2}{*}{ Autumn } & 2001 & $11.2(5.2-24.2)$ & $841,950(391,150-1,812,300)$ \\
\hline & 2002 & $11.4(5.3-24.3)$ & $852,680(399,240-1,821,100)$ \\
\hline Combined & & $11.2(6.8-18.5)$ & $842,280(511,420-1,387,200)$ \\
\hline
\end{tabular}


standard errors (SE) for combined estimates declined by $28 \%$ for spring and $33 \%$ for autumn, and $95 \%$ confidence intervals declined by $26 \%$ for spring and $40 \%$ for autumn.

For the four surveys, strip-transect density estimates were 6.9-16.3 gazelles $\mathrm{km}^{-2}$, or c. 500,000-1,200,000 animals in total (Table 4). The densities and total abundance of gazelles were similar to the distance sampling estimates, with similarly large confidence intervals that decreased when seasonal estimates were pooled, although the correlation of estimates among years was poor (Pearson correlation $=0.25$ ) and not significant.

\section{Discussion}

This study is the first time that consecutive population estimates have been made for Mongolian gazelles using a standardized protocol and including measures to estimate variation. Previous published attempts to count this species have provided only single point estimates or a small range of values, often without offering additional information as to how the data were obtained or how precise the estimates were, making comparisons difficult (Milner-Gulland \& Lhagvasuren, 1998; Reading et al., 1998). Also, estimates have been made for areas of varying size, sometimes apparently a subset of total range, such as ours, and at other times for the entire range.

Our estimate of $800,000-900,000$ gazelles (c. 10-11 gazelles $\mathrm{km}^{-2}$ ) over an area of $80,000 \mathrm{~km}^{2}$ of high-quality range are not at odds with several unpublished surveys conducted recently. In 1994 Mix (1994) and colleagues (unpubl. data cited in Milner-Gulland \& Lhagvasuren, 1998; Reading et al., 1998) used a large aircraft to survey gazelles over $475,000 \mathrm{~km}^{2}$ of their range, a survey area over six times larger than ours, but including less productive and sparsely populated areas. They estimated a total population of 2,670,000 gazelles. Reading et al. (1998) reported from local interviews that a population of 250,000-300,000 gazelles occurred in Dornod Aimag. In 2001 V. Kiriuluk (pers. comm.) made an educated guess that 300,000-500,000 gazelles remained throughout eastern Mongolia. In 2003 B. Lhagvasuren (pers. comm.) estimated 750,000 gazelles in all of Dornod. However, these estimates are difficult to use as comparisons because they are based largely on extrapolation from limited observations, from surveying only in known gazelle regions, or from surveys using unsuitable aircraft.

There are, however, also some limitations to the techniques we used to estimate gazelle numbers. At $250,000 \mathrm{~km}^{2}$, Mongolia's eastern steppe is approximately the size of the $\mathrm{UK}$, and the $80,000 \mathrm{~km}^{2}$ region we surveyed is approximately three times the size of the entire Serengeti ecosystem (Sinclair, 1979). Despite driving great distances, our line transects had coverage of only c. $1-2 \%$ of the entire survey area. Given this low coverage, and especially the high variation in herd size, each of our estimates had large confidence intervals (coefficient of variation of density, CV [D] was 36-43\%) but this does not mean that surveys with low precision are inaccurate (Mayer et al., 2002). Doubling the survey effort (i.e. combining years for a given season) improved the precision, but only by c. $35-40 \%$, and confidence limits remained wide (Tables 4 \& 5). In order to have estimates with a $20 \% \mathrm{CV}$, future surveys would have to be 4,206-5,662 km long (3.2-4.4 times the distances we drove), given the same sighting probability (length $=\{\text { known } \mathrm{CV}(\mathrm{D})\}^{2} /\{\text { desired } \mathrm{CV}(\mathrm{D})\}^{2}$; Buckland et al., 2001; Seddon et al., 2003). Another limitation of the survey is the difficulty of estimating numbers of gazelle in some herds because they can contain hundreds or thousands of animals, are moving, and are on a flat plain with many individuals abreast. Finally, point estimates for strip transect calculations seemed reasonable but high variation in gazelle group size and distribution are also likely to have made them imprecise.

Furthermore, the gazelle population in our survey region is not closed. Gazelles are highly mobile and migratory and there are few geophysical barriers that would prevent them from moving to the west of the study area, although the Kherlen River and high wire border fence virtually prevents all crossing (at least in summer and when gates are closed) in the rest of the region. Other migrant ungulates shift range significantly and unexpectedly; caribou Rangifer tarandus have been known to shift entire seasonal ranges due to changes in conditions limiting access to forage (Ferguson \& Messier, 2000). Thus, when we did not detect an expected increase in the population, due to the birth of calves, in the spring vs autumn 2002 surveys (assuming that point counts were accurate), we suspect that gazelle herds moved out of our survey area. Because we had no reason to believe that over-summer mortality was abnormally high (Olson, 2005), the drop in numbers by 341,000 between spring and autumn 2002 might have been due to movement out of the survey area. However, the estimates were not significantly different. Such apparent changes suggest that the gazelles move at a scale greater than the $80,000 \mathrm{~km}^{2}$ survey area, and/or that our estimates are not precise or accurate enough to distinguish between population changes and statistical variation.

We could not reliably detect changes in the population over the short-term, although continued monitoring over time would probably allow us to discern any long-term changes. Thus, surveys of the magnitude we conducted may not be enough to adequately monitor gazelle numbers, because once a negative trend is detected, it may possibly be too late (Milner-Gulland et al., 2003). Therefore, a conservative approach to interpreting these 
data is probably warranted; i.e., decreases in density estimates should be treated as such unless there is accurate information to accept another trend.

Our estimate of $800,000-900,000$ gazelles in a portion of the entire gazelle range indicates that the population is still relatively large. Ecologically this is important because gazelles are prey, for example, for wolves, eagles, and scavenging vultures on the steppe. Thus, a severe decline in the gazelle population could result in a cascade of ecological effects in the eastern steppe. Additionally, severe declines in the gazelle population would probably have a negative impact on traditional subsistence hunting practices.

Currently, there is no regular monitoring programme of the Mongolian gazelle population with an established protocol. In the absence of such a programme, setting of hunting quotas for what may appear to be a sustainable harvest (i.e. one that does not cause a decline in the population and promotes conservation) may simply be an example of unintended overkill (Murray, 2003; Zahler et al., 2004). More simply, if the population size is unknown but there is incentive to harvest because of market forces, it is likely that too many will be killed.

Disease outbreaks are known to cause sudden declines in Mongolian gazelles. Schaller \& Lhagvasuren (1998) described the loss of two year-classes, in addition to a large proportion of adults, to footrot Fusobacterum necroforum in autumn 1998. It is not clear what effect this had on population densities because of the absence of monitoring. Heavy poaching, in addition to years of high natural mortality, could cause a severe decrease in the population, and this could go unnoticed if there is no regular monitoring.

Monitoring of overall numbers alone, however, is unlikely to be sufficient to conserve gazelles, as seen from studies of other species. Saiga antelope Saiga tatarica have been relatively well monitored for over 20 years, but the last few monitoring efforts detected a precipitous and potentially unrecoverable crash in the population (because of highly skewed sex ratios due to excessive hunting of males; Milner-Gulland et al., 2003). If saiga over-harvest had been monitored and sufficient management efforts had been instituted earlier, however, successful conservation intervention may have occurred before the population collapse instead of after it. Tibetan antelope Pantholops hodgsonii, or chiru, had potential to provide a valuable sustainable source of income for residents of the Tibetan plateau from live-combing (vs recovery from dead animals) and selling the animals' fine wool. But the once estimated population of $1,000,000$ or more has decreased to perhaps fewer than 75,000 as a result of intense poaching for their wool (Schaller, 1998). Thus, similar to saiga and chiru, the monitoring of economic circumstances may be as important to Mongolian gazelle conservation as population monitoring.
Thus, in addition to developing an adequate population monitoring programme, an effective management and hunting law enforcement programme needs to be adopted and strictly adhered to. Otherwise, Mongolian gazelles may be monitored just long enough to record the population declining into oblivion. As our estimates apply to about one-third of the eastern steppe ecosystem, they only serve to demonstrate that the size of the Mongolian gazelle population is still large and that a diverse set of management and conservation options still exist. Gathering baseline information on the population size and long-term monitoring of a major large herbivore and umbrella or keystone species of the grasslands should be a priority for developing further management programmes that emphasize harvesting or habitat manipulation.

We recommend that surveys following our methodology be carried out as soon as possible throughout the gazelle's range, and that either May or AugustSeptember are the appropriate times for such surveys so that they do not disturb calving females (in June and July) or overtax gazelles during winter stress periods. Given gazelle densities, no lesser distances, and probably much greater distances, should be driven to help increase precision of population estimates and obtain information on distribution. The accuracy of our survey protocol should be verified by comparisons with accepted aerial survey methodologies once suitable aircraft become available. A regular (i.e. annual or biannual, depending on reports of disease outbreaks, severe winter weather or high poaching activity) population monitoring programme with observers trained in distance sampling and analysis should be adopted for the species throughout its range, whether on the ground or via aircraft. Such monitoring should be an integral part of the development of a comprehensive conservation programme for Mongolian gazelles.

\section{Acknowledgements}

Research was funded by the Wildlife Conservation Society and the UNDP/Government of Mongolia/ Eastern Steppes Biodiversity Project, and institutional support was provided by the University of Massachusetts and the National University of Mongolia. Thanks to Josh Ginsberg, Andrew Laurie and R. Samya who provided much needed support and advice while in the field, to Jargal, Erdenebulgan and Sarantuya for their help with surveys, and particularly to Baatarkhuu for driving every kilometre mentioned. S. DeStefano provided helpful comments on an earlier draft of this manuscript, and S. Buckland and an anonymous reviewer made many suggestions for improvement. 


\section{References}

Asian Development Bank (2002) Strategic Development Outline for Economic Cooperation Between People's Republic of China and Mongolia. Technical Report, Publication stock \# 110501. Asian Development Bank, Manila, Philippines.

Bannikov, A., Heptner, V. \& Nasimovich, V. (1961) The Mammals of the Soviet Union, Volume 1. Vysshaya Shkola Publishers, Moscow, Russia. [1988 English edition. Model Press, New Delhi, India]

Buckland, S.T., Anderson, D.R., Burnham, K.P., Laake, J.L., Borchers, D.L. \& Thomas, L. (2001) Introduction to Distance Sampling: Estimating Abundance of Biological Populations. Oxford University Press, Oxford, UK.

Drummer, T.D. \& McDonald. L.L. (1987) Size bias in line transect sampling. Biometrics, 43, 13-21.

Ferguson, M. \& Messier, F. (2000) Mass emigration of arctic tundra caribou from a traditional winter range: population dynamics and physical condition. Journal of Wildlife Management, 64, 168-178.

Finch, C. (1996) Mongolia's Wild Heritage. Avery Press, Boulder, USA. [Also available at http:/ / www.un-mongolia.mn/ archives/wildher/, accessed 8 Dec 2004]

Gunin, P., Vostokova, E.A., Dorofeyuk, N.I., Tarasov, P.E. \& Black. C.C. (2000) Assessing present day plant cover dynamics. In Vegetation Dynamics of Mongolia (eds P. Gunin, E.A. Vostokova, N.I. Dorofeyuk, P.E. Tarasov \& C.C. Black), pp. 131-163. Kluwer Academic Publishers, Dordrecht, The Netherlands.

Jiang, Z., Takatsuki, S., Zhongxin, G. \& Kun, J. (1998) The present status, ecology and conservation of the Mongolian gazelle, Procapra gutturosa: a review. Mammal Study, 23, 63-78.

Jigjidsuren, S. \& Johnson, D. (2003) Forage Plants in Mongolia. ADMON Publishing, Ulaanbaatar, Mongolia.

Lhagvasuren, B. \& Milner-Gulland, E.J. (1997) The status and management of the Mongolian gazelle Procapra gutturosa population. Oryx, 31, 127-134.

Mayer, M.S., Fuller, T.K., Deblinger, R.D. \& McDonald, J.E. Jr (2002) Can low-precision population and survival estimates of deer be accurate? Wildlife Society Bulletin, 30, 440-448.

Milner-Gulland, E.J. \& Lhagvasuren, B. (1998) Population dynamics of the Mongolian gazelle Procapra gutturosa: an historical analysis. Journal of Applied Ecology, 35, 240-251.

Milner-Gulland, E.J., Bukreeva, O.M., Coulson, T., Lushchekina, A.A., Kholodova, M.V., Bekenov, A.B. \& Grachev, I.A. (2003) Reproductive collapse in saiga antelope harems. Nature, 422, 135.

Mix, H. (1994) Mongolische Antilope. Projectgruppe Naturschutz International e.V. Unpublished Report. Nature Conservation International, Berlin, Germany.

Murray, M.G. (2003) Overkill and sustainable use. Science, 299, 1851-1853.

Olson, K.A., Fuller, T.K., Schaller, G.B., Lhagvasuren, B. \& Odonkhuu, D. (2005) Reproduction, neonatal weights, and first-year survival of Mongolian gazelles (Procapra gutturosa). Journal of Zoology, 265, 227-233.

Penttila, W.C. (1994) The recoverable oil and gas resources of Mongolia. Journal of Petroleum Geology, 17, 89-98.
Reading, R.P., Mix, H., Lhagvasuren, B. \& Tseveenmyadag, N. (1998) The commercial harvest of wildlife in Dornod Aimag, Mongolia. Journal of Wildlife Management, 62, 59-71.

Sampildendev, H. (2000) Mongolian custom of worshipping nature. In Nomads and Use of Pastures Today (ed. J. Tsolmon), pp. 119-121. International Institute for the Study of Nomadic Civilization, Ulaanbaatar, Mongolia.

Schaller, G.B. \& Lhagvasuren, B. (1998) A disease outbreak in Mongolian gazelles. Gnusletter, 17, 17-18.

Schaller, G.B. (1998) Wildlife of the Tibetan Steppe. University of Chicago Press, Chicago, USA.

Scharf, K. \& Enkhbold, E. (2002) Hunting in Eastern Mongolia. Final Report. UNDP/Eastern Steppe Biodiversity Project, Ulaanbaatar, Mongolia.

Sinclair, A.R.E. (1979) The Serengeti environment. In Serengeti, Dynamics of an Ecosystem (eds A.R.E. Sinclair \& M.

Norton-Griffiths), pp. 31-45. The University of Chicago Press. Chicago, USA.

Seddon, P.J., Ismail, K., Shobrak, M., Ostrowski, S. \& Magin, C. (2003) A comparison of derived population estimate, mark-resighting and distance sampling methods to determine the population size of a desert ungulate, the Arabian oryx. Oryx, 37, 286-294.

Thomas, L., Laake, J.L., Strindberg, S., Marques, F.F.C., Buckland, S.T., Borchers, D.L., Anderson, D.R., Burnham, K.P., Hedley, S.L. \& Pollard, J.H. (2003) Distance 4.1 Release 2. Research Unit for Wildlife Population Assessment, University of St. Andrews, UK. Http:/ / www.ruwpa.stand.ac.uk/distance/ [accessed 24 August 2004].

Xiaoming, W., Helin, S., Junghui, B. \& Ming, L. (1997) Recent history and status of the Mongolian gazelle in Inner Mongolia, China. Oryx, 31, 120-126.

Zahler, P., Olson, K., Ganzorig, K., Boldbaatar, B., Schaller, G.B., Grigg, G., Popple, T., Payne, N., Draisma, M., Hopwood, P. \& Odonkhuu, D. (2004) Management of Mongolian gazelles as a sustainable resource. Mongolian Journal of Biological Science, 1, 48-55.

\section{Biographical sketches}

Kirk A. Olson is working on wildlife conservation and management issues in Mongolia at a variety of levels by investigating ecological and sociological problems and opportunities.

Todd K. Fuller collaborates with students and colleagues on studies of mammal natural history and population ecology.

George B. Schaller currently conducts field work in several Asian countries and in various circumstances to further species and ecosystem conservation.

Daria Odonkhuu studies mammal behaviour, ecology, and conservation in Mongolia.

Martyn G. Murray is an ecologist, conservationist and biodiversity consultant who has forged friendships and professional links with consultants and scientists from all regions of the world. 